\title{
DIELECTRIC DISSIPATION FACTOR IN THREE-CORE POWER CABLES
}

\author{
Ivan Kostiukov \\ National Technical University "Kharkiv Polytechnic Institute", Kharkiv, Ukraine, \\ E-mail: iakostiukow@gmail.com
}

\begin{abstract}
This article is devoted to the analysis of components of variance of the results of measurements of dielectric dissipation factor of insulation layers between the conductive elements of the construction of three core power cables with paper impregnated insulation in a common sheath. The analysis of components of variance was carried out by applying presented relations for the direct calculation of the dielectric dissipation factor. The accuracy of presented relations for the calculation of variance components was verified. The results of carried out analysis have shown that the variance of the dielectric dissipation factor measurements is mostly determined by the variances of multiplication of measurements of aggregate values of dielectric dissipation factor and coefficients depending on the partial capacitances of tested three core cable. capacitance.

Key words: Testing of insulation, Power cable diagnostics, Insulation deterioration, Aggregate measurements, Electrical
\end{abstract}

\section{Introduction}

The value of the dielectric dissipation factor is pretty often used for solving engineering issues which concern the assessment of the quality of insulation of power cables [1-3] and communication cables [4, 5]. Measurements of this parameter often should be carried out not only for power cables of a comparatively simple coaxial construction but also for a pretty spread type of three core power cables with paper insulation in a common metal sheath. For the mentioned type of power cables in [6], there have been established criteria for the determination of the extent of electrical insulation deterioration. Due to the sophisticated construction which causes numerous parasitic couplings concerning the examined layer of insulation, measurements of dissipation factor of layers of insulation between the electrically conductive elements of construction is complicated. Developed techniques for the determination of dielectric parameters of insulation are based on the applying of both direct [7] and aggregate [8] measurements. According to [7] the direct measurements are possible for the case of sufficiently constrained values of parasitic capacitances of the examined layer of insulation. The determination of the parameters of examined layers of insulation utilizing aggregate measurements allows avoiding the influence of parasitic parameters on the results of carried out measurements. The drawback of such techniques is the unacceptable impact of errors of measurements of aggregate values of examined parameters on the individual values of calculated characteristics of examined layers [9]. The applying of aggregate measurements for the determination of partial capacitances and corresponding values of dielectric dissipation factor has been substantiated in [10-12]. In [10] the analysis of the stability of solutions of systems of equations for the calculation of partial capacitances and dielectric dissipation factor for fluctuations of the right side of the system of equations was carried out. In $[11,12]$ methods of forming systems of linear algebraic equations for the determination of the parameters of insulation layers by applying aggregate measurements and also issues of regularization of systems of equations for the determination of insulation parameters from badly conditioned systems of equations have been considered. This article is dedicated to the solving of issue which concerns the estimation on components of variance of the results of dielectric dissipation factor calculation

\section{Shortcomings}

Despite the pretty detailed development of issues that concern the determination of partial capacitances and corresponding values of dielectric dissipation factor based on the applying of aggregate measurements, issues which concern the estimation of uncertainties and components of variance remain unconsidered.

\section{Objective of the Study}

The analysis of components of variance of the results of measurements of dielectric dissipation factor of layers of insulation between the electrically conductive elements of the construction of three core power cables.

\section{Dielectric Dissipation Factor of the Cables \\ 4.1 Methodology of measurement of dielectric dissipation factor of layers of insulation}

Fig. 1 presents the equivalent scheme of insulation of three core power cables in a common metal sheath [11]. For the presented scheme developed and described in [10-12] methods of measurement of individual parameters of insulation layers according to 
the terminology of $[6,13]$ is based on the formation of the system of equations by applying the following schemes of insulation examination:

- "conductor across two other conductors and sheath". In this case, the test voltage is consecutively applied to the layer of insulation formed between the each of power cable conductors and, connected and with the sheath, two other conductors of power cable. Obtained by applying this scheme of examination aggregate values of electrical capacitance and dielectric dissipation factor will be denoted as $C_{A}, C_{B}, C_{C}$ and $\operatorname{tg} \delta_{A}$, $\operatorname{tg} \delta_{B}, \operatorname{tg} \delta_{C}$. In this case, $C_{A}$, and $\operatorname{tg} \delta_{A}$ denote the aggregate values of electrical capacitance and dielectric dissipation factor measured by applying a test voltage to the layer of

Fig. 1. Equivalent scheme of layers of insulation between the electrically conductive elements of the construction of three core power cables in a common metal sheath: $C_{A B}, C_{C B}, C_{A C}$ are the values of partial capacitances between the conductors of power cable, $C_{A G}, C_{C G}, C_{B G}$ is the values of partial capacitances between the conductors and the sheath of power cable, $R_{A B}, R_{C B}, R_{A C}$ are the values of electrical resistance due to dielectric power losses in insulation gaps between the conductors of power cable, $R_{A G}, R_{B G}, R_{C G}$ are the values of electrical resistance due to dielectric power losses in insulation layers between the conductors and the sheath of power cable

After carried out by applying described schemes of examination 6 measurements it is possible to form a system of equations for the determination of partial capacitances presented on Fig. 1 insulation layers. The estimation of values of dielectric dissipation factor is done based on the results of the theory of non-uniform dielectrics. According to these results for two switched in parallel electrical capacitances with power losses the equivalent value of dielectric dissipation factor can be calculated according to [12]:

$$
\operatorname{tg} \delta=\operatorname{tg} \delta_{1}\left(\frac{C_{1}}{C_{1}+C_{2}}\right)+\operatorname{tg} \delta_{2}\left(\frac{C_{2}}{C_{1}+C_{2}}\right),
$$

where $C_{1}$ and $C_{2}$ correspondingly denote the values of the electrical capacitance of the first and second capacitor, $\operatorname{tg} \delta_{1}$ and $\operatorname{tg} \delta_{2}$ are the values of dielectric dissipation factor of the first and second switched in parallel capacitors. In this case, the values of the dielectric dissipation factor of insulation layers between the electrically conductive elements of the construction of three core power cables can be determined by solving the system of equations:

$$
\mathbf{T} \cdot \mathbf{d}=\mathbf{t},
$$

where $\mathbf{t}$ is the vector that contains the results of measurements of aggregate values of dielectric dissipation factor:

$\mathbf{t}=\left[\operatorname{tg} \delta_{A}, \operatorname{tg} \delta_{B}, \operatorname{tg} \delta_{C}, \operatorname{tg} \delta_{A-B}, \operatorname{tg} \delta_{B-C}, \operatorname{tg} \delta_{A-C}\right]^{\mathrm{T}}, \mathbf{d}$ is the vector which contains the unknown values of dielectric dissipation factor of insulation layers between the insulation between the conductor $A$ connected with the metal sheath, and conductors $B, C$ of the power cable.

- "two conductors across the conductor and the sheath". In this case, the test voltage is applied to the layer of insulation between the two connected conductors of the power cable and the third conductor connected to the sheath. For this case, the values of the electric capacitance and tangent of the dielectric loss angle will be denoted as $C_{A-B}, C_{B-C}, C_{A-C}$, and $\operatorname{tg} \delta_{A-B}, \operatorname{tg} \delta_{B-}$ $C, \operatorname{tg} \delta_{A-C}$. In such a notation, $C_{A-B}$ and $\operatorname{tg} \delta_{A-B}$ will denote the insulation parameters measured for the case of a test voltage applied to the insulation layer between the connected conductors $A$ and $B$ (of power cable) and connected with the sheath conductor $C$.

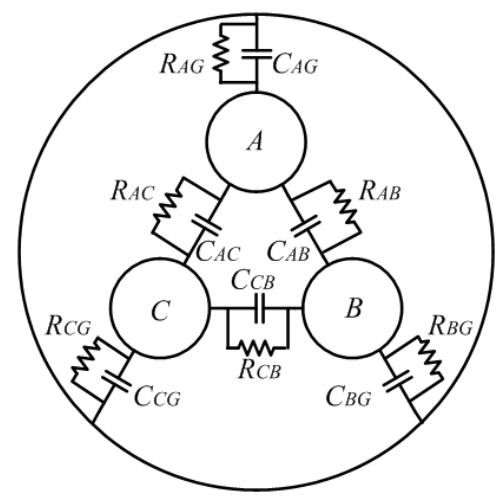

conductors of power cable and the conductors and the sheath of power cable: $\mathbf{d}=\left[\operatorname{tg} \delta_{A B}, \operatorname{tg} \delta_{B C}, \operatorname{tg} \delta_{A C}, \operatorname{tg} \delta_{A G}\right.$, $\left.\operatorname{tg} \delta_{B G}, \operatorname{tg} \delta_{C G}\right]^{\mathrm{T}}$ and rows and columns of matrix $\mathbf{T}$ can be determined according to:

$$
\mathbf{T}=\left(\begin{array}{cccccc}
a_{1} & 0 & a_{2} & a_{3} & 0 & 0 \\
a_{4} & a_{5} & 0 & 0 & a_{6} & 0 \\
0 & a_{7} & a_{8} & 0 & 0 & a_{9} \\
0 & a_{10} & a_{11} & a_{12} & a_{13} & 0 \\
a_{14} & 0 & a_{15} & 0 & a_{16} & a_{17} \\
a_{18} & a_{19} & 0 & a_{20} & 0 & a_{21}
\end{array}\right),
$$

where all coefficients $a_{1} . . a_{21}$ are determined based on previously calculated values of partial capacitances between the conductors of power cable and between the conductors and the sheath of power cable and can be calculated as components of vectors $\mathbf{a}_{1-3}$.. $\mathbf{a}_{18-21}$ according to the relations:

$$
\begin{gathered}
\mathbf{a}_{\mathbf{1}-\mathbf{3}}=\frac{1}{C_{A B}+C_{A C}+C_{A G}} \cdot \mathbf{C}_{\mathbf{1}-\mathbf{3}}, \\
\mathbf{a}_{\mathbf{4}-\mathbf{6}}=\frac{1}{C_{A B}+C_{B C}+C_{B G}} \cdot \mathbf{C}_{\mathbf{4}-\mathbf{6}}, \\
\mathbf{a}_{\mathbf{7}-\mathbf{9}}=\frac{1}{C_{B C}+C_{A C}+C_{C G}} \cdot \mathbf{C}_{\mathbf{7 - 9}}, \\
\mathbf{a}_{\mathbf{1 0}-\mathbf{1 3}}=\frac{1}{C_{B C}+C_{A C}+C_{A G}+C_{B G}} \cdot \mathbf{C}_{\mathbf{1 0 - 1 3}}, \\
\mathbf{a}_{\mathbf{1 4}-\mathbf{1 7}}=\frac{1}{C_{A B}+C_{A C}+C_{B G}+C_{C G}} \cdot \mathbf{C}_{\mathbf{1 4}-\mathbf{1 7}},
\end{gathered}
$$




$$
\mathbf{a} \mathbf{1 8 - 2 1}=\frac{1}{C_{A B}+C_{B C}+C_{A G}+C_{C G}} \cdot \mathbf{C}_{\mathbf{1 8}-\mathbf{2 1}},
$$

where components of vectors $\mathbf{a}_{1-3} . \mathbf{a}_{\mathbf{1 8 - 2 1}}$ can be determined according to the relations: $\mathbf{a}_{1-3}=\left[\begin{array}{lll}a_{1} & a_{2} & a_{3}\end{array}\right]$, $\mathbf{a}_{4-6}=\left[\begin{array}{lll}a_{4} & a_{5} & a_{6}\end{array}\right], \mathbf{a}_{7-9}=\left[\begin{array}{lll}a_{7} & a_{8} & a_{9}\end{array}\right], \mathbf{a}_{10-13}=\left[\begin{array}{llll}a_{10} & a_{11} & a_{12} & a_{13}\end{array}\right]$, $\mathbf{a}_{14-17}=\left[\begin{array}{llll}a_{14} & a_{15} & a_{16} & a_{17}\end{array}\right], \mathbf{a}_{18-21}=\left[\begin{array}{llll}a_{18} & a_{19} & a_{20} & a_{21}\end{array}\right]$, whereas components of vectors $\mathbf{C}_{\mathbf{1 - 3}}$.. $\mathbf{C}_{\mathbf{1 8 - 2 1}}$ can be determined according to the relations: $\mathbf{C}_{\mathbf{1 - 3}}=\left[C_{A B} C_{A C} C_{A G}\right], \mathbf{C}_{\mathbf{4 - 6}}=$ $\left[C_{A B} C_{B C} C_{B G}\right], \mathbf{C}_{\mathbf{7 - 9}}=\left[C_{B C} C_{A C} C_{C G}\right], \mathbf{C}_{\mathbf{1 0 - 1 3}}=\left[C_{B C} C_{A C}\right.$ $\left.C_{A G} C_{B G}\right], \mathbf{C}_{\mathbf{1 4 - 1 7}}=\left[C_{A B} C_{A C} C_{B G} C_{C G}\right], \mathbf{C}_{\mathbf{1 8 - 2 1}}=\left[C_{A B} C_{B C}\right.$ $\left.C_{A G} C_{C G}\right]$.

4.2 Relations for the calculation of dielectric dissipation factor of layers of insulation

The solution of the system of equations (2) can be obtained according to (10):

$$
\mathbf{d}=\mathbf{T}^{-\mathbf{1}} \mathbf{t}
$$

here rows and columns of matrix $\mathbf{T}^{-1}$ can be determined according to:

$$
\mathbf{T}^{-\mathbf{1}}=0.5 \cdot\left(\begin{array}{cccccc}
\frac{1}{a_{1}} & \frac{1}{a_{4}} & 0 & -k_{1} & 0 & 0 \\
0 & \frac{1}{a_{5}} & \frac{1}{a_{7}} & 0 & -k_{2} & 0 \\
\frac{1}{a_{2}} & 0 & \frac{1}{a_{8}} & 0 & 0 & -k_{3} \\
0 & -k_{4} & -k_{5} & \frac{1}{a_{12}} & 0 & \frac{1}{a_{20}} \\
-k_{6} & 0 & -k_{7} & \frac{1}{a_{13}} & \frac{1}{a_{16}} & 0 \\
-k_{8} & -k_{9} & 0 & 0 & \frac{1}{a_{17}} & \frac{1}{a_{21}}
\end{array}\right),
$$

here coefficients $k_{1} . . k_{9}$ can be calculated by applying the presented in Table 1 relations.

Taking into consideration (11) the relations for the calculation of dielectric dissipation factor explicitly can be written according to (12-17):

$$
\begin{gathered}
\operatorname{tg} \delta_{A B}=0.5 \cdot\left(\frac{\operatorname{tg} \delta_{A}}{a_{1}}+\frac{\operatorname{tg} \delta_{B}}{a_{4}}-k_{1} \operatorname{tg} \delta_{A-B}\right) \\
\operatorname{tg} \delta_{B C}=0.5 \cdot\left(\frac{\operatorname{tg} \delta_{B}}{a_{5}}+\frac{\operatorname{tg} \delta_{C}}{a_{7}}-k_{2} \operatorname{tg} \delta_{B-C}\right) \\
\operatorname{tg} \delta_{A C}=0.5 \cdot\left(\frac{\operatorname{tg} \delta_{A}}{a_{2}}+\frac{\operatorname{tg} \delta_{C}}{a_{8}}-k_{3} \operatorname{tg} \delta_{A-C}\right), \\
\operatorname{tg} \delta_{A G}=0.5 \cdot\left(\frac{\operatorname{tg} \delta_{A-B}}{a_{12}}+\frac{\operatorname{tg} \delta_{A-C}}{a_{20}}-k_{4} \operatorname{tg} \delta_{B}-k_{5} \operatorname{tg} \delta_{C}\right), \\
\operatorname{tg} \delta_{B G}=0.5 \cdot\left(\frac{\operatorname{tg} \delta_{A-B}}{a_{13}}+\frac{\operatorname{tg} \delta_{B-C}}{a_{16}}-k_{6} \operatorname{tg} \delta_{A}-k_{7} \operatorname{tg} \delta_{C}\right) \\
\operatorname{tg} \delta_{C G}=0.5 \cdot\left(\frac{\operatorname{tg} \delta_{B-C}}{a_{17}}+\frac{\operatorname{tg} \delta_{A-C}}{a_{21}}-k_{8} \operatorname{tg} \delta_{A}-k_{9} \operatorname{tg} \delta_{B}\right),
\end{gathered}
$$

It can be seen from (12-17) that the mathematical expectation of the results of determination of dielectric dissipation factor of insulation layers between the conductors of power cable and between the conductors and the sheath of power cable will be determined by the results of calculation of scalar product between the rows of matrix $\mathbf{T}^{-1}$ and the results of measurements of aggregate values of dielectric dissipation factor $\mathbf{t}$.

\subsection{The results of measurements of aggregate} values of dielectric dissipation factor

The results of measurements of aggregate values of dielectric dissipation factor which have been used for the determination of components of variance and standard deviation of measurement results are presented in Fig. 2. All measurements have been carried out for three core power cables of AAShv 6-3 $\times 150$ type after 24 years of operation on a Khmelnytsky nuclear power plant by applying an immittance meter E7-22 for the case of frequency of applied voltage equal to $100 \mathrm{~Hz}$. $\delta$

Relations for the calculation of elements $k_{1} . . k_{9}$ of matrix $\mathrm{T}^{-1}$

\begin{tabular}{|c|c|c|c|}
\hline Coefficient & Relation for the calculation & Coefficient & Relation for the calculation \\
\hline$k_{1}$ & $\frac{C_{B C}+C_{A C}+C_{A G}+C_{B G}}{C_{A B}}$ & $k_{6}$ & $\frac{C_{A B}+C_{A C}+C_{A G}}{C_{B G}}$ \\
\hline$k_{2}$ & $\frac{C_{A B}+C_{A C}+C_{B G}+C_{C G}}{C_{B C}}$ & $k_{7}$ & $\frac{C_{B C}+C_{A C}+C_{C G}}{C_{B G}}$ \\
\hline$k_{3}$ & $\frac{C_{A B}+C_{B C}+C_{A G}+C_{C G}}{C_{A C}}$ & $k_{8}$ & $\frac{C_{A B}+C_{A C}+C_{A G}}{C_{C G}}$ \\
\hline$k_{4}$ & $\frac{C_{A B}+C_{B C}+C_{B G}}{C_{A G}}$ & $\frac{C_{A B}+C_{B C}+C_{B G}}{C_{C G}}$ \\
\hline$k_{5}$ & \multicolumn{2}{c}{$\frac{C_{B C}+C_{A C}+C_{C G}}{C_{A G}}$} \\
\hline
\end{tabular}




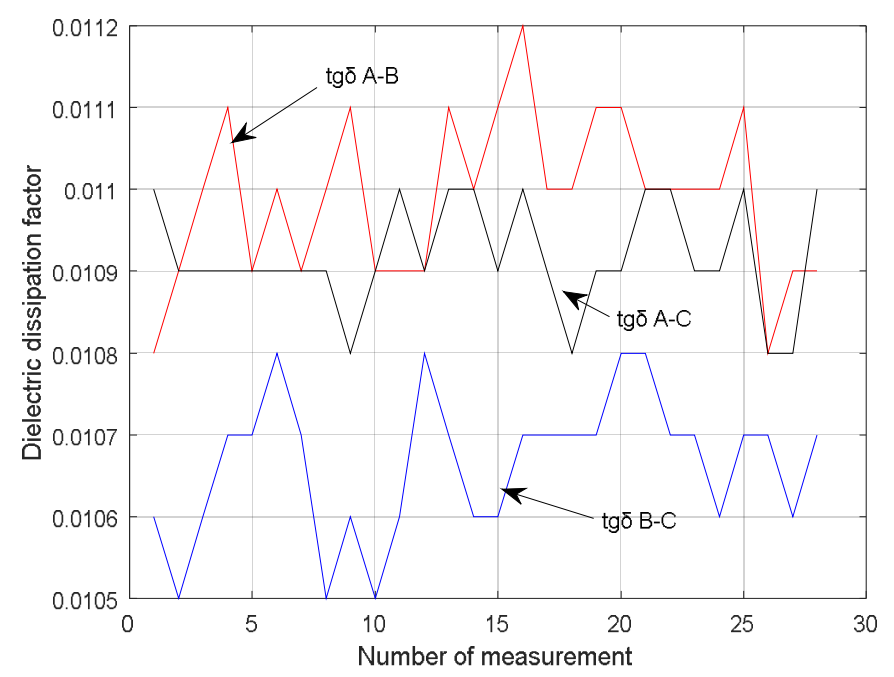

Fig. 2. The results of iterated measurements of aggregate values of dielectric dissipation factor by applying a scheme of examination: "two conductors across the conductor and the sheath"

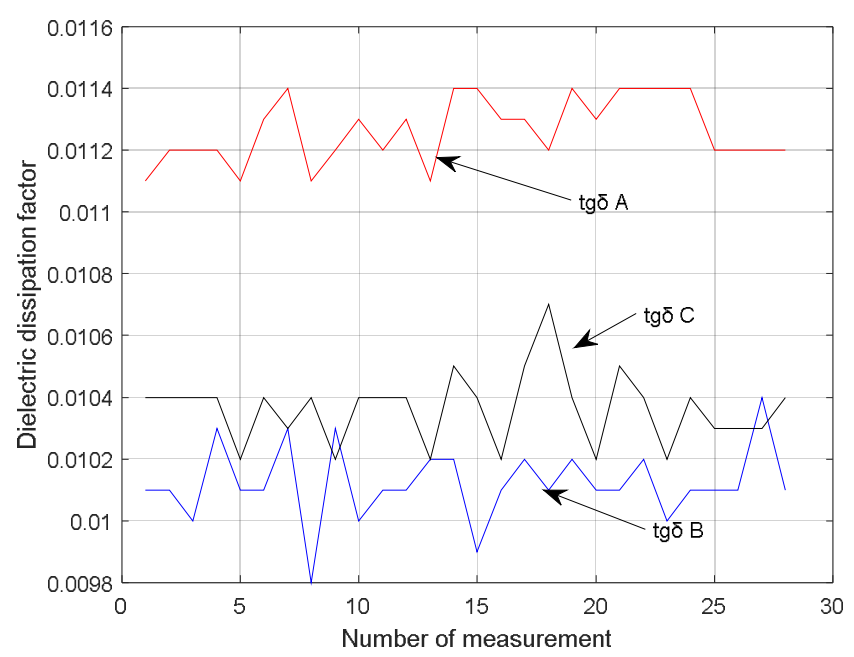

Fig. 3. The results of iterated measurements of aggregate values of dielectric dissipation factor by applying a scheme of examination: "conductor across two other conductors and sheath"

4.4 The relations for the calculation of the variance of the results of determination of the values of dielectric dissipation factor by applying aggregate measurements

The relations for the variance of the results of calculation of values of dielectric dissipation factor of insulation layers in a three-core power cable in the article will be analyzed on the example of calculating the variance of dielectric dissipation factor of insulation gap between the conductors $A$ and $B$ of the power cable $\left(\operatorname{tg} \delta_{A B}\right)$. Fig. 4 presents the histogram of the distribution of the obtained results, which were used for the calculation of variance components and the analysis of the accuracy of formulas for its calculation. All the results presented in Fig. 4 were obtained by calculating the value of $\operatorname{tg} \delta_{A B}$ according to (12).

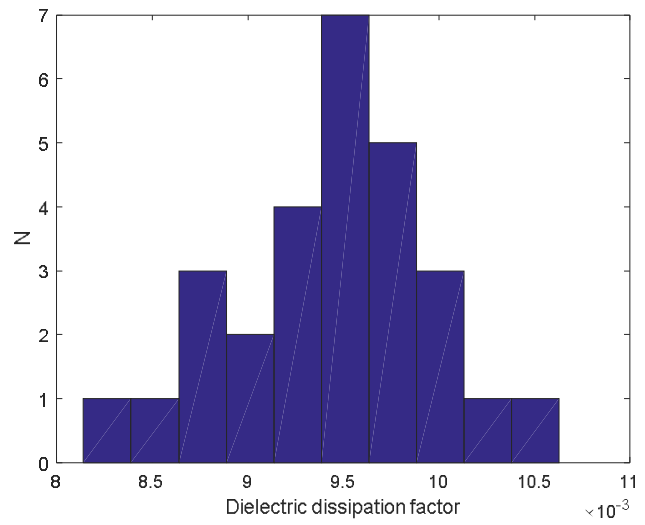

Fig.4. Histogram of values of dielectric dissipation factor of the insulation layer between the conductors $A$ and $B$ of the power cable 
From (12) it can be concluded that the variance of the obtained results in general case will be determined by the variances of multiplication of random variables which are the results of measurements of aggregate values of dielectric dissipation factor $\left(\operatorname{tg} \delta_{A}, \operatorname{tg} \delta_{B}, \operatorname{tg} \delta_{A-B}\right)$ and random variables, which are the results of measurement of aggregate values of electrical capacitance and the results of measurements of partial capacitances of insulation gaps in the power cable $\left(a_{1}^{-1}\right.$, $a_{4}{ }^{-1}$, and $k_{1}$ ). Taking into consideration (12), in the general case the relation for the calculation of the variance of the results of determination of $\operatorname{tg} \delta_{A B}$ can be written in the following form:

$$
\begin{gathered}
D_{1}\left(\operatorname{tg} \delta_{A B}\right)=\frac{1}{4}\left(D\left(p_{1}\right)+D\left(p_{2}\right)+D\left(p_{3}\right)+:\right. \\
\left.+2 K\left(p_{1} p_{2}\right)-2 K\left(p_{1} p_{3}\right)-2 K\left(p_{2} p_{3}\right)\right) \\
p_{1}=\operatorname{tg} \delta_{A} a_{1}^{-1} \\
p_{2}=\operatorname{tg} \delta_{B} a_{4}^{-1} \\
p_{3}=k_{1} \operatorname{tg} \delta_{A-B} .
\end{gathered}
$$

where $D\left(p_{1}\right), D\left(p_{2}\right), D\left(p_{3}\right)$ denote the variances of determined according to (19-21) random variables $p_{1}, p_{2}$, and $p_{3}$, while $K\left(p_{1} p_{2}\right), K\left(p_{1} p_{3}\right)$ and $K\left(p_{2} p_{3}\right)$ denote the covariance coefficients between the corresponding values $p_{1}, p_{2}$ and $p_{3}$. In simplified form, without taking into consideration the covariance between the random variables $p_{1}, p_{2}$ and $p_{3}$, the relation for the determination of components of variance of the results of $\operatorname{tg} \delta_{A B}$ calculation can be written according to (22):

$$
D_{2}\left(\operatorname{tg} \delta_{A B}\right)=0.25 \cdot\left(D\left(p_{1}\right)+D\left(p_{2}\right)+D\left(p_{3}\right)\right),
$$

Calculation of $D\left(p_{1}\right), D\left(p_{2}\right), D\left(p_{3}\right)$ can be carried out based on applying the relations for the calculation of the variance of the result of multiplication of two independent or dependent random variables. In the first case $D\left(p_{1}\right), D\left(p_{2}\right)$, and $D\left(p_{3}\right)$ can be calculated based on a known relation [14 p. 213]. For the case of applying of mentioned formula the relations for the calculation of $D\left(p_{1}\right), D\left(p_{2}\right)$ and $D\left(p_{3}\right)$ can be written according to $(23-25)$ :

$$
\begin{aligned}
D\left(p_{1}\right)= & D\left(a_{1}^{-1}\right) D\left(\operatorname{tg} \delta_{A}\right)+\left(M\left(a_{1}^{-1}\right)\right)^{2} D\left(\operatorname{tg} \delta_{A}\right)+ \\
& +\left(M\left(\operatorname{tg} \delta_{A}\right)\right)^{2} D\left(a_{1}^{-1}\right) \\
D\left(p_{2}\right)= & D\left(a_{4}^{-1}\right) D\left(\operatorname{tg} \delta_{B}\right)+\left(M\left(a_{4}^{-1}\right)\right)^{2} D\left(\operatorname{tg} \delta_{B}\right)+ \\
& +\left(M\left(\operatorname{tg} \delta_{B}\right)\right)^{2} D\left(a_{4}^{-1}\right), \\
D\left(p_{3}\right)= & D\left(k_{1}\right) D\left(\operatorname{tg} \delta_{A-B}\right)+\left(M\left(k_{1}\right)\right)^{2} D\left(\operatorname{tg} \delta_{A-B}\right)+ \\
& +\left(M\left(\operatorname{tg} \delta_{A-B}\right)\right)^{2} D\left(k_{1}\right),
\end{aligned}
$$

where $M\left(k_{1}\right), M\left(a_{1}^{-1}\right), M\left(a_{4}^{-1}\right), M\left(\operatorname{tg} \delta_{A}\right), M\left(\operatorname{tg} \delta_{B}\right)$ and $M\left(\operatorname{tg} \delta_{A-B}\right)$ denote the mathematical expectation of values $k_{1}, a_{1}^{-1}, a_{4}{ }^{-1}, \operatorname{tg} \delta_{A}, \operatorname{tg} \delta_{B}$, and $\operatorname{tg} \delta_{A-B}$. For the case of two dependent random variables calculation can be carried out based on presented in [15] relation. For the case of applying of mentioned formula the relations for $D\left(p_{1}\right)$, $D\left(p_{2}\right)$ and $D\left(p_{3}\right)$ can be written according to (26-26):

$$
\begin{gathered}
D\left(p_{1}\right)=D\left(a_{1}^{-1}\right) D\left(\operatorname{tg} \delta_{A}\right)\left(\left(1+r_{a 1 \operatorname{tg} \delta A}^{2}\right)+\left[\frac{\left(M\left(a_{1}^{-1}\right)\right)^{2}}{D\left(a_{1}^{-1}\right)}+\frac{\left(M\left(\operatorname{tg} \delta_{A}\right)\right)^{2}}{D\left(\operatorname{tg} \delta_{A}\right)}+2 r_{a 1 \operatorname{tg} \delta}^{2}\left(\frac{M\left(a_{1}^{-1}\right)}{\sigma\left(a_{1}^{-1}\right)}\right)\left(\frac{M\left(\operatorname{tg} \delta_{A}\right)}{\sigma\left(\operatorname{tg} \delta_{A}\right)}\right)\right],\right. \\
D\left(p_{2}\right)=D\left(a_{4}^{-1}\right) D\left(\operatorname{tg} \delta_{B}\right)\left(\left(1+r_{a 4 t g \delta B}^{2}\right)+\left[\frac{\left(M\left(a_{4}^{-1}\right)\right)^{2}}{D\left(a_{4}^{-1}\right)}+\frac{\left(M\left(\operatorname{tg} \delta_{B}\right)\right)^{2}}{D\left(\operatorname{tg} \delta_{H}\right)}+2 r_{a 4 \operatorname{tg} \delta B}^{2}\left(\frac{M\left(a_{4}^{-1}\right)}{\sigma\left(a_{4}^{-1}\right)}\right)\left(\frac{M\left(\operatorname{tg} \delta_{B}\right)}{\sigma\left(\operatorname{tg} \delta_{B}\right)}\right)\right]\right), \\
D\left(p_{3}\right)=D(k) D\left(\operatorname{tg} \delta_{A-B}\right)\left(\left(1+r_{k \operatorname{tg} \delta A-B}^{2}\right)+\left[\frac{(M(k))^{2}}{D(k)}+\frac{\left(M\left(\operatorname{tg} \delta_{A-B}\right)\right)^{2}}{D\left(\operatorname{tg} \delta_{A-B}\right)}+2 r_{k \operatorname{tg} \delta A-B}^{2}\left(\frac{M(k)}{\sigma(k)}\right)\left(\frac{M\left(\operatorname{tg} \delta_{A-B}\right)}{\sigma\left(\operatorname{tg} \delta_{A-B}\right)}\right)\right]\right),
\end{gathered}
$$

where $r_{a 1 \operatorname{tg} \delta A,} \quad r_{a 4 \operatorname{tg} \delta B}, \quad r_{k \operatorname{tg} \delta A-B}$ denote correlation coefficients between the values $a_{1}{ }^{-1}$ and $\operatorname{tg} \delta_{A}, a_{4}{ }^{-1}$ and $\operatorname{tg} \delta_{B}$ and also $k$ and $\operatorname{tg} \delta_{A-B}, \sigma(k), \sigma\left(a_{1}^{-1}\right), \sigma\left(a_{4}^{-1}\right), \sigma\left(\operatorname{tg} \delta_{B}\right)$, $\sigma\left(\operatorname{tg} \delta_{A}\right), \quad \sigma\left(\operatorname{tg} \delta_{A-B}\right)$ correspondingly denote standard deviations of $k, a_{1}^{-1}, a_{4}^{-1}, \operatorname{tg} \delta_{B}, \operatorname{tg} \delta_{A}, \operatorname{tg} \delta_{A-B}$. Thus, estimation of variance components was carried out by applying relations $(18,22)$, whereas calculation of $D\left(p_{1}\right)$, $D\left(p_{2}\right)$, and $D\left(p_{3}\right)$ was carried out by the direct calculation of variance and also based on applying relations (23-25) and (26-28).

\section{Results and Discussion}

The accuracy of applying each of the presented relations for the calculation of variance was determined by comparison of calculated based on its applying standard deviation with the standard deviation of data presented in Fig. 4. The variance for the data on Fig. 4 was calculated according to (29) [14]:

$$
D\left(\operatorname{tg} \delta_{A B}\right)=\frac{1}{N-1} \sum_{i=1}^{N}\left(\operatorname{tg} \delta_{A B i}-M\left(\operatorname{tg} \delta_{A B}\right)\right)^{2},
$$

where $N$ is the number of carried out measurements, $M\left(\operatorname{tg} \delta_{A B}\right)$ is the mean value of the results of $\operatorname{tg} \delta_{A B}$ measurements, $\operatorname{tg} \delta_{A B i}$ is the value of $\operatorname{tg} \delta_{A B}$ from the calculated according to formula (12) array of results. The results analysis are given in Table 2.

From the results of the calculations presented in Table 2, it can be concluded that for the shown in Fig. 4 
results neglect by the components of variance of the results of calculation that arise from the existence of a mutual covariance between the random variables $p_{1}, p_{2}$ and $p_{3}$, leads to the overestimation of calculated standard deviation. The relative error of calculation is equal to $9.1 \%$. The results of calculations according to (18) coincide with the results of calculation of standard deviation obtained by direct calculation of variance according to (29). It should be noted that for the case of applying (18) the components of the variance $D\left(p_{1}\right)$,
$D\left(p_{2}\right)$, and $D\left(p_{3}\right)$ have been calculated directly, i.e. by applying similar to (29) formulas. At the same time, calculation of $D\left(p_{1}\right), D\left(p_{2}\right)$, and $D\left(p_{3}\right)$, both for the case of applying given in [14 p. 213] formula for the variance of the product of two independent random variables, and for the case of applying proposed in [15] relation for the calculation of the variance of the product of two dependent random variables, leads to errors in the estimation of standard deviation and, correspondingly, in the variance of measurement results.

Table 2

The results of comparative analysis of various relations for computing the variance of $\operatorname{tg} \delta_{A B}$.

\begin{tabular}{|c|c|c|}
\hline $\begin{array}{c}\text { Relation for computing the variance } \\
\text { used for the calculation of standard } \\
\text { deviation. }\end{array}$ & Results & Relative error of calculation, \% \\
\hline Relation (29) & $5.5 \cdot 10^{-4}$ & - \\
\hline Relation (18) & $5.5 \cdot 10^{-4}$ & 9.1 \\
\hline Relation (22) & $6 \cdot 10^{-4}$ & -2.2 \\
\hline $\begin{array}{c}\text { Relation }(18) \\
\text { in case of calculation of } D\left(p_{1}\right), D\left(p_{2}\right) \text { and } \\
D\left(p_{3}\right) \text { according to }(23-25)\end{array}$ & $5.38 \cdot 10^{-4}$ & -2.4 \\
\hline $\begin{array}{c}\text { Relation }(18) \\
\text { in case of calculation of } D\left(p_{1}\right), D\left(p_{2}\right) \text { and } \\
D\left(p_{3}\right) \text { according to }(26-28)\end{array}$ & & 7.8 \\
\hline $\begin{array}{c}\text { Relation }(22) \text { in case of calculation of } D\left(p_{1}\right), \\
D\left(p_{2}\right) \text { and } D\left(p_{3}\right) \text { according to }(23-25)\end{array}$ & $5.37 \cdot 10^{-4}$ & 7.6 \\
\hline $\begin{array}{c}\text { Relation }(22) \\
\text { in case of calculation of } D\left(p_{1}\right), D\left(p_{2}\right) \text { Ta } \\
D\left(p_{3}\right) \text { according to }(26-28)\end{array}$ & & \\
\hline
\end{tabular}

\section{Conclusions}

The results of carried out analysis have shown that for the presented in this article measurement results the variance of the results of calculations of individual values of dielectric dissipation factor of insulation layers between the conductive elements of the construction of three-core power cables in a common sheath is mainly determined by the variances of the results of multiplication of measured aggregate values of dielectric dissipation factor and the results of measurement of partial capacitances. Neglect by the covariance between the results of measurements of aggregate values of dielectric dissipation factor and dependent on partial capacitances coefficients for presented in the article measurement results leads to equal to $9.1 \%$ relative error of estimation of standard deviation.

\section{Conflict of Interests}

The author does not declare financial or any other conflicts of interest concerning this article.

\section{References}

[1] J. C. Fothergill, T. Liu, S. J. Dodd, L. A. Dissado, U. H. Nilsson "The measurement of very low conductivity and dielectric loss in XLPE cables: a possible method to detect degradation due to thermal aging" IEEE Transactions on Dielectrics and Electrical Insulation, vol. 18 no. 5, pp. 15441553, 2011 DOI: 10.1109/TDEI.2011.6032823

[2] A. Ponniran, M. S. Kamarudin, "Study of the performance of underground XLPE cables in service based on tan delta and capacitance measurements". Proc. of 2 IEEE International Conference on Power and Energy. Johor Bahru, Malaysia, pp. 39-43, 2008 DOI: 10.1109/PECON.2008.4762442

[3] D. Bolliger, "Simultaneous partial discharge and tan delta measurements" Proc. of 2018 IEEE/PES Transmission and Distribution Conference and Exposition Denver, USA, pp. 38-42, 2018 DOI: 10.1109/TDC.2018.8440325

[4] G. V. Bezprozvannych, A. G. Kyessayev "Relaxations losses in polyethylene insulation of coaxial cable structure during aging in high humidity conditions" Electrical Engineering \& Electromechanics, no. 2, 38-42, 2016 DOI: 10.20998/2074-272X.2016.2.07

[5] G. V. Bezprozvannych, I. A. Mirchuk "The evaluation of the possibility of the normal operation of cables based on twisted pairs with PVC jacket under the conditions of high humidity and temperature" Electrical Engineering \& Electromechanics, no.5, pp. 49-53, 2017 DOI: 10.20998/2074272X.2017.5.08

[6] G. V. Bezprozvannych, E.S. Moskvitin "Estimation criteria for degree of paper-impregnated insulated power cable aging” Electrical Engineering \& Electromechanics, no. 4, pp. $32-36,2013$ (in Russian) 
[7] B. G. Naboka, G. V. Bezprozvannych, A.S. Shtangej, O.N. Radchenko "Method for direct measurements of the partial capacitance parameters of multicore cables" Bulletin of NTU «KhPI», no. 42, pp. 80 - 86, 2005 (in Russian)

[8] G.V. Bezprozvannych "Dielectric scanning of the transverse structure of multicore cables using the cumulative measurement method" Technical Electrodynamics, no. 3, pp. 30 - 36, 2008 (in Russian)

[9] E.T. Volodars'kij, V.V. Kuharchuk, V. O. Podzharenko. Metrological support of measurements and control. Tutorial. Vinnytsia: VDTU Publ, 2001, 219 p. (in Ukrainian)

[10] B. G. Naboka, G. V. Bezprozvannych, S. V. Rudakov "Analysis of the stability of the method for restoring the parameters of the equivalent circuit of a three-phase cable from the results of indirect measurements", Information Processing Systems, Vol. 20, no. 4, pp. 192 - 197, 2002 (in Russian)

[11] E.S. Moskvitin "Control of processes of power cables with paper impregnated insulation aging by measu- rements of dielectric properties of insulation layers" Bulletin of $N T U$ «KhPI», no. 3, pp. 95 - 106, 2011 (in Russian)

[12] G. V. Bezprozvannych, S. V. Rudakov, E.S. Moskvitin. Prevention of emergencies by monitoring the state of the insulation of multicore cables by the parameters of partial capacitances and the tangent of the angle of dielectric losses. Kharkiv: «Urban publ.», 2013, 132 p. (in Russian)

[13] G. V. Bezprozvannych, E.S. Moskvitin, A. G. Kyessayev "The absorption characteristics of the phase and zone impregnated insulation of power cable at direct voltage" Electrical Engineering \& Electromechanics, no.5, pp. 63-68, 2013 (in Russian)

[14] E. S. Ventcel'. Probability theory. Publishing House "State publishing house of physical and mathematical literature", 1958, 464 C. (in Russian)

[15] V. P. Kotel'nikov "Calculation of the variance of the product of two correlated random variables" Review of Applied and Industrial Mathematics, Vol. 24, no.1, p. 54, 2017 (in Russian) 